\title{
Erasure Behavior of Isothermal Physical Aging Effect below Glass Transition Temperature in a Fully Cured E poxy Resin. Differential Scanning Calorimetry Measurement
}

\author{
Jong Keun LEE ${ }^{\dagger}$ and Jae Young HwANG \\ Department of Polymer Science and Engineering, Kumoh National Institute of Technology Kumi, Kyungbuk 730-701, Korea
}

(Received October 21, 2002; Accepted December 11, 2002)

\begin{abstract}
A mixture of diglycidyl ether of bisphenol A (DGEBA) epoxy resin and amine curing agent with a stoichiometric ratio was fully cured at $220^{\circ} \mathrm{C}$ for $30 \mathrm{~h}\left(T_{\mathrm{g} \infty}=179^{\circ} \mathrm{C}\right)$. The fully cured specimen was isothermally aged at various aging temperatures $\left(T_{\mathrm{a}}=90-150^{\circ} \mathrm{C}\right)$ for aging time $\left(t_{\mathrm{a}}\right)$ of $1000 \mathrm{~min}$, and effect of the isothermal physical aging was investigated by differential scanning calorimetry (DSC). The effect of the physical aging appeared as a sharp endothermic peak in the glass transition temperature $\left(T_{\mathrm{g}}\right)$ region at higher aging temperatures but a small broad peak below $T_{\mathrm{g}}$ at lower aging temperatures. In this work, erasure below $T_{\mathrm{g}}$ of the isothermal physical aging effect was examined for a specimen aged at $T_{\mathrm{a}}=150^{\circ} \mathrm{C}$ by heating to different erasure temperatures $\left(T_{\mathrm{er}}=155-170^{\circ} \mathrm{C}\right)$ above the aging temperature but below the glass transition temperature for different erasure times $\left(t_{\mathrm{er}}=10-60 \mathrm{~min}\right)$. Enthalpy relaxation was obtained from area difference of DSC thermograms between aged and de-aged specimen, and used to investigate the effect of heating to $T_{\mathrm{er}}$. It was found that the heating to $T_{\mathrm{er}}$ affects differently to the previous aging at $T_{\mathrm{a}}=150^{\circ} \mathrm{C}$. When the aged specimen was heated at $T_{\mathrm{er}}=155^{\circ} \mathrm{C}$ near $T_{\mathrm{a}}$, the heating leads to additional aging to the previous aging. However, the previous aging effect was partially erased with residual aging during heating at higher erasure temperatures. Amount and rate of the erasure became larger with increasing $T_{\mathrm{er}}$. After the erasure, a small amount of further aging occurred with erasure time. This result indicates that there is competition between aging and de-aging at an aging temperature between aging temperature and glass transition temperature.
\end{abstract}

KEY WORDS Epoxy / Physical Aging / Erasure / Differential Scanning Calorimetry (DSC) /

Physical aging induces change of physical and mechanical properties through spontaneous densification process below the glass transition temperature $\left(T_{\mathrm{g}}\right)$ in amorphous polymers. The change of properties is observed by volume, enthalpy, mechanical and dielectric response. It is interesting to know the range of temperature in property changes affected by isothermal physical aging at a certain temperature. It is reported that whole storage modulus and $\tan \delta v s$. temperature curve from dynamic mechanical analysis (DMA) shifts up and down with aging time, respectively, when isothermally aged at a temperature below $T_{\mathrm{g}}{ }^{1}$ Also, the thermal expansion behavior of a fully cured epoxy before and after sub- $T_{\mathrm{g}}$ aging was examined by thermomechanical analysis (TMA). The aged specimen exhibited a lesser volume in the whole glassy state compared to non-aged one. This indicates that effect of isothermal aging occurs in an entire range of temperature from below the glassy state relaxation $\left(T_{\beta}\right)$ to $T_{\mathrm{g}}$. However, Gillham and coworkers ${ }^{2-6}$ using torsional braid analysis (TBA) technique measuring intermittent modulus and logarithmic decrement have shown that effect of isothermal physical aging is localized in a limited temperature range (i.e., in the vicinity of the aging temperature). The localization of aging effect has also observed in other works using DMA. ${ }^{7,8}$

Implication of the localization in effect of aging has been discussed in earlier papers. ${ }^{2,6}$ In a molecular level, intermediate length scale within chain is involved in the relaxation process, approaching slowly with time to an equilibrium state, while shorter and longer than the intermediate are free to move and frozen in place, respectively, during aging. The intermediate length scale elements at the aging time become restricted as physical aging proceeds. Upon heating, the intermediates regain the mobility that they had before aging at the $T_{\mathrm{a}}$ and at higher temperature they also acquire the same freedom to move freely as those elements of a short length scale.

Therefore, localization due to the relaxation of intermediate length in chain suggests that it may not be necessary to eliminate aging effect by heating an aged material to a temperature above its glass transition temperature that is considered to completely erase aging effect. Erasure of localized isothermal physical aging effect below the glass transition temperature but above aging temperature has been observed by means of TBA. ${ }^{6}$ The phenomenon that property changes due to physical aging can be erased below $T_{\mathrm{g}}$ is practically very important. For example, when a glassy material is exposed to temperature cycling between a high

${ }^{\dagger}$ To whom correspondence should be addressed (E-mail: jklee@kumoh.ac.kr). 
temperature $\left(T_{\text {on }}\right)$ and a low temperature $\left(T_{\text {off }}\right)$, such as in epoxy-encapsulated electronic devices, changes due to aging at $T_{\text {on }}$ are accumulated and those at $T_{\text {off }}$ are eliminated at $T_{\text {on }}$. Therefore, the density of a material increases with time at $T_{\text {on }}$ whereas density consecutively increases and decreases at $T_{\text {off }}$. The erasure below $T_{\mathrm{g}}$ also suggests that the stresses developed during the physical aging of engineering materials may be eliminated without complete softening.

All the studies on localization and erasure of the isothermal aging effect were mostly done by means of observation of dynamic mechanical properties. In this work, we intend to show and confirm the erasure of effect of isothermal physical aging below the glass transition temperature using one of the most common methods in physical aging studies, DSC measurement, for a fully cured epoxy/amine system.

\section{EXPERIMENTAL}

\section{Reactants}

The chemical structures of diglycidyl ether of bisphenol A (DER 332, 174 g/eq., Dow Chemical Co.) and trimethylene glycol di- $p$-aminobenzoate (TMAB, $78.5 \mathrm{~g} /$ eq., Air Products Corp.) are represented in Figure 1. A stoichiometric mixture (epoxy/ $\mathrm{NH}=1 / 1)$ was formed by mixing (without solvent) at $100^{\circ} \mathrm{C}$ for $15 \mathrm{~min}$.

\section{Technique}

After fully curing the initially unreacted liquid at $220^{\circ} \mathrm{C}$ for $35 \mathrm{~h}$, DSC (Dupont 910) measurements were made to examine the effect of isothermal physical aging from 30 to $220^{\circ} \mathrm{C}$ at a heating rate of $10^{\circ} \mathrm{C} \mathrm{min}^{-1}$. A hermetic pan containing about $10 \mathrm{mg}$ of the unreacted mixture was sealed tightly and placed in the DSC cell. The maximum $T_{\mathrm{g}}$ of the fully cured sample $\left(T_{\mathrm{g} \infty}\right)$ was $179^{\circ} \mathrm{C}$ in this experiment. The atmosphere was a slow-flowing dry nitrogen. A single specimen was used through the whole experiment. Note that the glassy state relaxation $\left(T_{\beta}\right)$ measured by TBA is $\sim-30{ }^{\circ} \mathrm{C}$ for this sample. ${ }^{4}$

\section{Temperature-Time Profile}

The temperature-time profiles for DSC experiment in this study are shown in Figure 2. Profile I in Figure 2 is used to examine the effect of isothermal physical aging. A sealed DSC pan containing the fully cured specimen $\left(T_{\mathrm{g} \infty}=179^{\circ} \mathrm{C}\right.$ from DSC) was heated in an external oven at $220^{\circ} \mathrm{C}$ (i.e., above $T_{\mathrm{g} \infty}$ ) for $15 \mathrm{~min}$ to eliminate previous thermal history, and then quenched and held for $15 \mathrm{~min}$ in powdered dry ice maintained at $-68^{\circ} \mathrm{C}$. (Solvent such as acetone was not used for the cooling

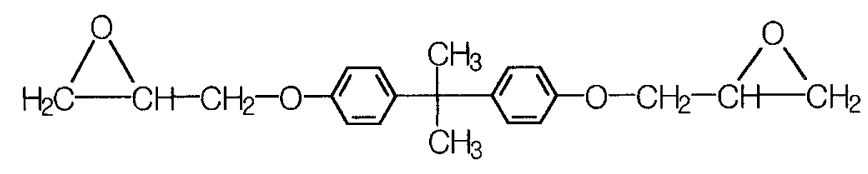

Diglycidyl Ether of Bis-phenol A

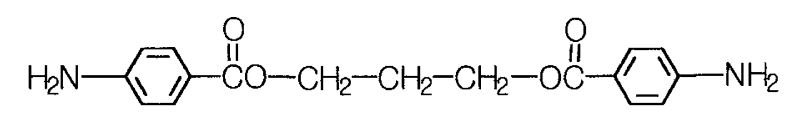

Trimethylene Glycol Di-p-aminobenzoate

Figure 1. Chemical structures of reactants.
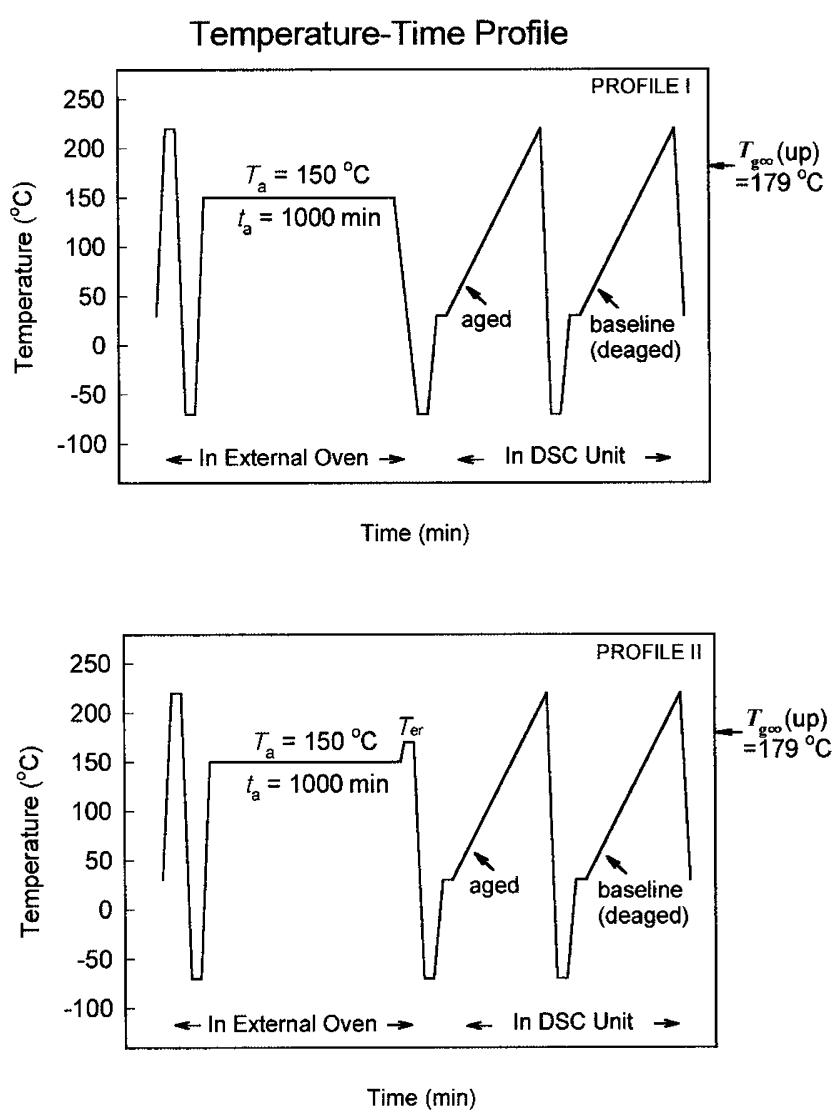

Figure 2. Time-temperature profiles used in this study.

medium because the solvent may affect to the specimen in the DSC pan). The quenched DSC pan was immediately put into another external oven preheated at $150{ }^{\circ} \mathrm{C}$ in order for the cured specimen to be isothermally aged at $150^{\circ} \mathrm{C}$ for $t_{\mathrm{a}}=1000 \mathrm{~min}$, followed by being quenched as before in powdered dry ice. The DSC pan, taken out from dry ice after $15 \mathrm{~min}$, was kept at room temperature for about $20 \mathrm{~min}$ to remove any condensed water vapor on the surface of the DSC pan. Then the DSC pan was placed into the DSC cell and scanned twice from 30 to $220^{\circ} \mathrm{C}$ to obtain the aged and de-aged (baseline) DSC behavior.

As shown in Profile II to examine the effect of era- 
sure of isothermal physical aging, the aged sample at $150^{\circ} \mathrm{C}$ was moved to an external oven preheated at an erasure temperature $\left(T_{\mathrm{er}}=155,160,165\right.$, and $\left.170^{\circ} \mathrm{C}\right)$ for different aging times $\left(t_{\mathrm{er}}\right)$ from 10 to $60 \mathrm{~min}$, and then quenched as before in powdered dry ice. After $15 \mathrm{~min}$ in the dry ice, the sample was kept at room temperature for about $20 \mathrm{~min}$ and then the DSC pan was placed into the DSC cell and scanned up twice from 30 to $220^{\circ} \mathrm{C}$ to obtain the aged and de-aged (baseline) DSC behavior as before. Comparison of the two uptemperature scans was made to examine the erasure of aging effect $v s . T_{\text {er }}$ and $t_{\text {er }}$. Segments in an external oven and DSC unit are marked in Figure 2.

A relatively high aging temperature (i.e., $T_{\mathrm{a}}=$ $150{ }^{\circ} \mathrm{C}$ ) and a rapid cooling rate (i.e., dry ice quenching) were necessary in this experiment because the effect of isothermal physical aging is so small or difficult to observe at low isothermal aging temperatures and at low rates of cooling by means of DSC. The rapid cooling was achieved by quenching into the dry ice from the external oven since the cooling rate in the DSC unit equipped with a mechanical cooling system is limited.

In raising the aging temperature $\left(T_{\mathrm{a}}\right)$, a temperature gap between $T_{\mathrm{a}}$ and $T_{\mathrm{g}}$ should be allowed for heating to an erasure temperature. The aging temperature and time were determined from a series of preliminary experiments. All specimens in the external oven were heated under an atmosphere of dry nitrogen after purging two times by the dry nitrogen. The heating rate for the DSC up-temperature scans was $10^{\circ} \mathrm{C} \mathrm{min}^{-1}$ with a slow dry external nitrogen flow.

\section{RESULTS AND DISCUSSION}

The DSC technique has been used to study the isothermal physical aging of epoxy thermosets. ${ }^{1,9-11}$ An effect of physical aging for a specimen isothermally aged near $T_{\mathrm{g}}$ appears normally in a DSC scan as an endothermic peak in the glass transition region. However, for aging temperatures well below $T_{\mathrm{g}}$ only a small endothermic peak appears below the glass transition in subsequent temperature scans. ${ }^{1,7,11}$ Up-temperature DSC scans of an aged and de-aged specimen are shown in Figure 3. Aging effect of $T_{\mathrm{a}}=150{ }^{\circ} \mathrm{C}$ and $t_{\mathrm{a}}=$ 1000 min appears as a sharp maximum superimposed on the heat capacity step, which corresponds to the glass transition of de-aged specimen. In this study, a relaxation enthalpy was obtained from the area difference between the aged and the de-aged specimen of the DSC curves, which is related to the amount of isothermal physical aging.

\section{DSC Thermograms for Aged and De-aged Specimen $\left(T_{\mathrm{a}}=150^{\circ} \mathrm{C}, t_{\mathrm{a}}=1000 \mathrm{~min}\right)$}

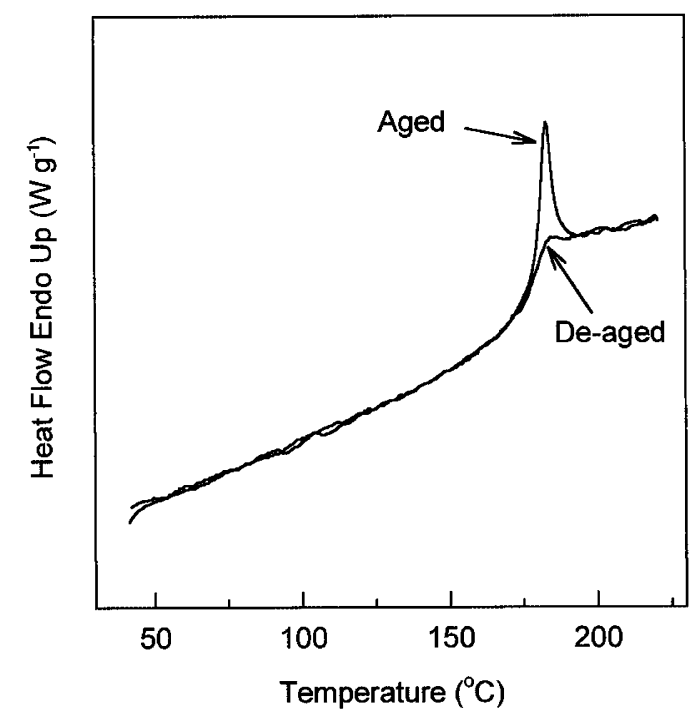

Figure 3. DSC thermograms of aged (at $150^{\circ} \mathrm{C}$ for $1000 \mathrm{~min}$ ) and de-aged specimen.

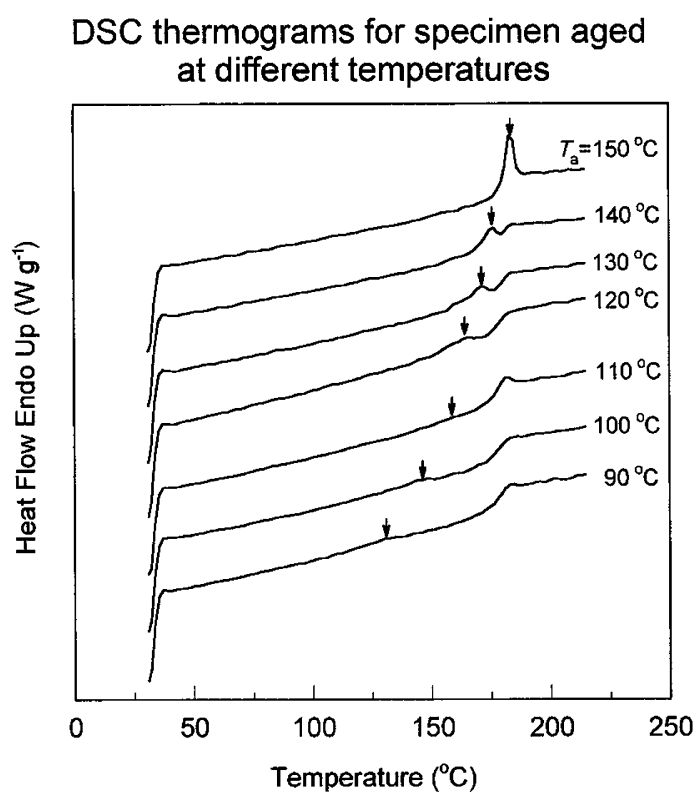

Figure 4. DSC thermograms of a specimen aged at different aging temperatures $\left(t_{\mathrm{a}}=1000 \mathrm{~min}\right)$.

\section{Isothermal Physical Aging at Different Aging Temper- atures}

After eliminating prehistory of the fully cured epoxy sample completely by heating $220^{\circ} \mathrm{C}$ for $15 \mathrm{~min}$, specimen was subsequently aged at different aging temperatures $\left(T_{\mathrm{a}}=90,100,110,120,130,140\right.$, and $\left.150^{\circ} \mathrm{C}\right)$ for an aging time $t_{\mathrm{a}}=1000 \mathrm{~min}$ as shown in temperaturetime profile I in Figure 2. Figure 4 displays DSC temperature scans for isothermally aged specimen at the different aging temperatures. Perturbation in the form of endothermic peak due to the isothermal ag- 
Enthlapy Relaxation Peak Temperature vs. Aging Temperature

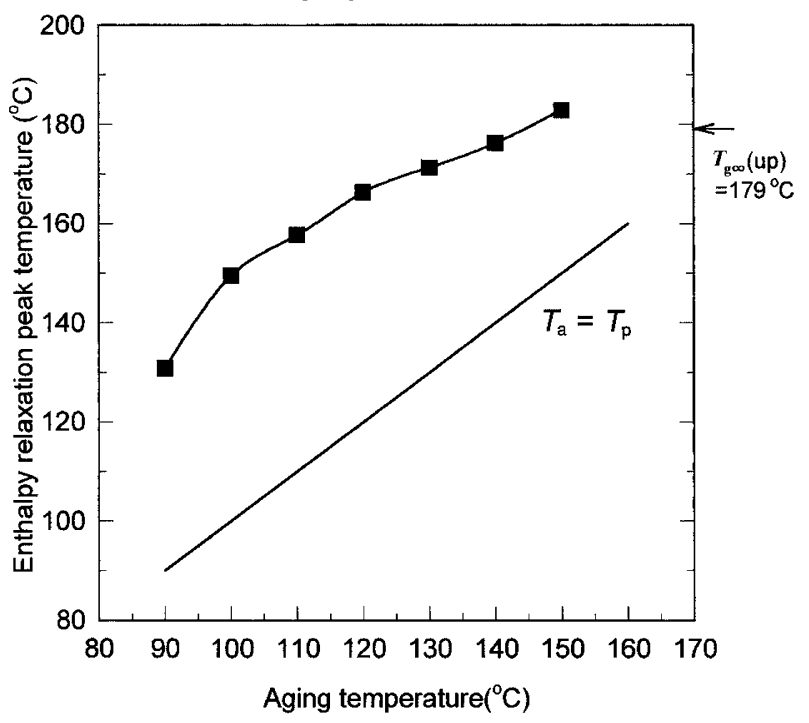

Figure 5. Enthalpy relaxation peak temperature $v s$. aging temperature of a specimen aged for $t_{\mathrm{a}}=1000 \mathrm{~min}$.

ing appeared on the DSC curves for aged specimens as marked by arrows in Figure 4 . Above $T_{\mathrm{a}}=130^{\circ} \mathrm{C}$, distinct and rather sharp endothermic peak was observed in the step transition region (i.e., glass transition), but below $T_{\mathrm{a}}=120^{\circ} \mathrm{C}$ broad and small peak below the glass transition temperature. As aging temperature is raised, the endothermic peak temperature increases.

Figure 5 has the endothermic peak temperature $\left(T_{\mathrm{p}}\right)$ determined from DSC curves in Figure $4 v s$. aging temperature. A line $T_{\mathrm{a}}=T_{\mathrm{p}}$ corresponds to the case when the aging temperature is equal to the peak temperature. This result indicates that the peak temperature due to the isothermal aging effect occurs about $30-50{ }^{\circ} \mathrm{C}$ above aging temperature and increases almost linearly with aging temperature in the range of 100 to $150^{\circ} \mathrm{C}$.

\section{Erasure of Isothermal Aging Effect}

According to the previous works, physical aging effect is localized in a limited temperature range ${ }^{2-6}$ and can be removed by raising temperature below glass transition temperature but above aging temperature by means of a mechanical oscillation method such as TBA. ${ }^{6}$ In this study, DSC experiment using the timetemperature profile II in Figure 2 was made to investigate the erasure behavior of the isothermal aging effect below the glass transition temperature.

Fully cured specimen was isothermally aged at $T_{\mathrm{a}}=$ $150^{\circ} \mathrm{C}$ for $t_{\mathrm{a}}=1000 \mathrm{~min}$, followed by heating to erasure temperature $\left(T_{\text {er }}\right)$ of $155,160,165$, and $170^{\circ} \mathrm{C}$ for erasure time $\left(t_{\mathrm{er}}\right)$ of up to $60 \mathrm{~min}$ in an external oven. The specimen was subsequently placed into DSC cell and scanned twice from 30 to $220^{\circ} \mathrm{C}$. Typical DSC

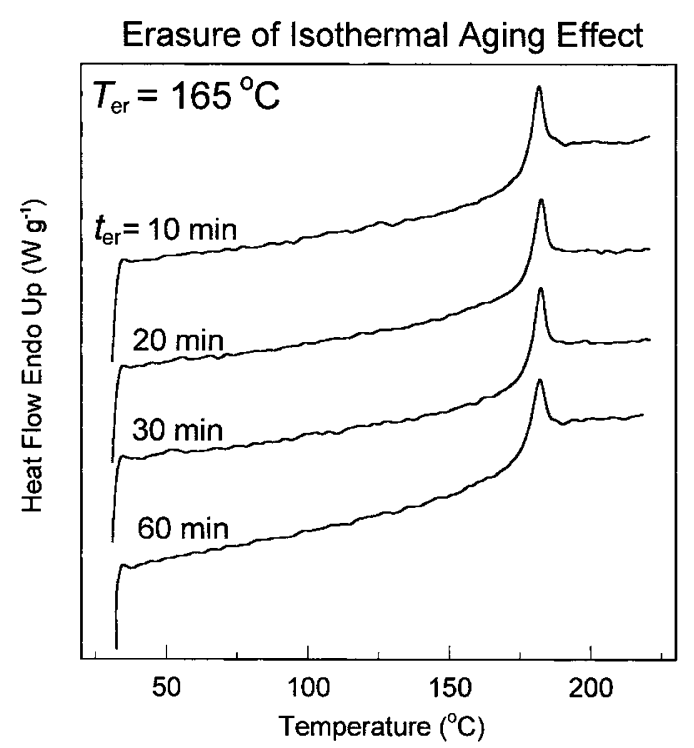

Figure 6. Typical DSC thermograms of a specimen aged for different erasure temperatures $\left(T_{\mathrm{er}}=165^{\circ} \mathrm{C}\right)$ and times $\left(T_{\mathrm{a}}=\right.$ $\left.150{ }^{\circ} \mathrm{C}, T_{\mathrm{a}}=1000 \mathrm{~min}\right)$.

thermogram is represented in Figure 6 for an aged specimen heated at $T_{\mathrm{er}}=165^{\circ} \mathrm{C}$ for different erasure times. Although the sharp endothermic peak due to the isothermal physical aging takes place at $179 \pm 2{ }^{\circ} \mathrm{C}$ for all erasure times, the peak intensity seems to be affected by the heating to the erasure temperature.

The enthalpy relaxation from the area difference between the aged specimen without erasing and after erasing at all erasure temperatures and times and de-aged specimen was obtained and the results are plotted in Figure 7. Aged sample without erasure, i.e., $t_{\mathrm{er}}=0$, has enthalpy relaxation of $1.8 \mathrm{~J} \mathrm{~g}^{-1}$. At the lowest erasure temperature, i.e., $T_{\mathrm{er}}=155^{\circ} \mathrm{C}$, which is close to $T_{\mathrm{a}}$, the enthalpy relaxation value increased with erasure time. However, the situation becomes different above the aging temperature. At $T_{\mathrm{er}}=160^{\circ} \mathrm{C}$, the value decreased rather slowly up to $30 \mathrm{~min}$ to $1.3 \mathrm{~J} \mathrm{~g}^{-1}$ and then increased up to $1.8 \mathrm{~J} \mathrm{~g}^{-1}$ by the erasure time of $60 \mathrm{~min}$. As $T_{\text {er }}$ is raised to $165^{\circ} \mathrm{C}$, the enthalpy relaxation decreased to $1.0 \mathrm{~J} \mathrm{~g}^{-1}$ after $25 \mathrm{~min}$ of erasure time and slightly increased up to $t_{\mathrm{er}}=60 \mathrm{~min}$. At the highest erasure temperature $T_{\mathrm{er}}=170^{\circ} \mathrm{C}$, which is close to the glass transition temperature (i.e., $T_{\mathrm{g} \infty}=179^{\circ} \mathrm{C}$ ), the relaxation value decreased rapidly to $0.5 \mathrm{~J} \mathrm{~g}^{-1}$ by heating for $t_{\mathrm{er}}=10 \mathrm{~min}$ and almost no change thereafter. Increase of enthalpy relaxation at $T_{\mathrm{er}}=155^{\circ} \mathrm{C}$ means that additional aging occurs during heating at the erasure temperature to previous aging at $150{ }^{\circ} \mathrm{C}$. The decrease of the enthalpy relaxation value at higher erasure temperatures does indicate the erasure of the previous aging effect at $150^{\circ} \mathrm{C}$. Note that a larger amount of aging effect is more rapidly removed at higher erasure temperatures. Note also that there is residual aging effect 
Enthalpy Relaxation vs. Erasure Time

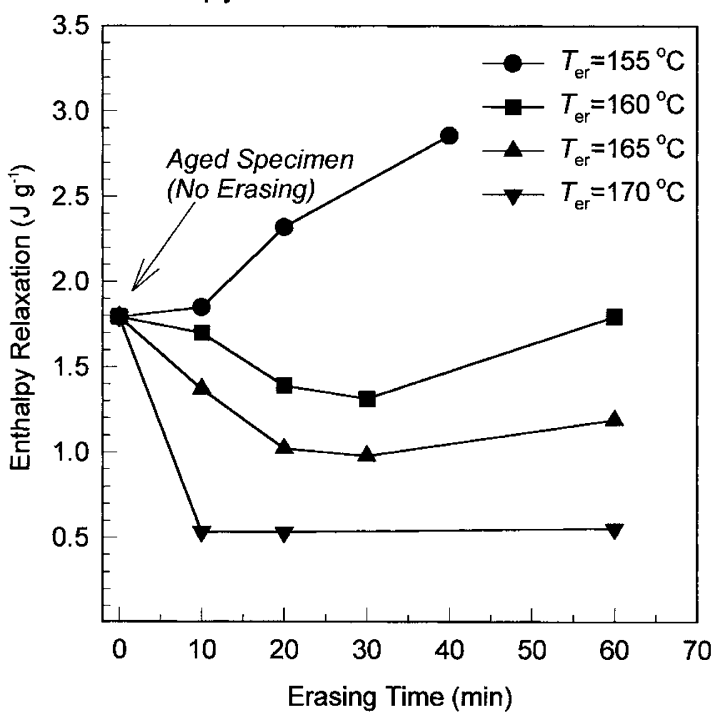

Figure 7. Enthalphy relaxation vs. erasure time at different erasure temperatures.

after erasure, indicating that the aging effect can not be completely eliminated. Therefore, erasure of previous aging effect is dominant at higher erasure temperature and shorter erasure time, while additional aging occurs at lower erasure temperature and longer erasure time.

The results of sub- $T_{\mathrm{g}}$ isothermal aging and subsequent heating at temperatures between $T_{\mathrm{a}}$ and $T_{\mathrm{g}}$ show that there is a partial removal of the effect of isothermal physical aging by the heating. It is of interest to examine the effects of sequential isothermal heating at two different temperatures on erasure behavior. Figure 8 has DSC thermograms for specimen isothermally aged at two sequential aging temperatures at $T_{\mathrm{a} 2}=150^{\circ} \mathrm{C}$ after $T_{\mathrm{a} 1}=120^{\circ} \mathrm{C}(120 \rightarrow 150)$ and vise versa $(150 \rightarrow 120)$ for $1000 \mathrm{~min}$ each. In Figure 4, a small/broad peak at around $155^{\circ} \mathrm{C}$ and a sharp peak in step transition region near $179^{\circ} \mathrm{C}$ occurred after separate aging at $T_{\mathrm{a} 1}$ and $T_{\mathrm{a} 2}$, respectively. Figure 8 shows that relaxation peak from aging at $120^{\circ} \mathrm{C}$ was eliminated by the increase of aging temperature to $150^{\circ} \mathrm{C}(120 \rightarrow 150)$, while both endothermic peaks existed after a reverse temperature sequence $(150 \rightarrow 120)$.

The sequential aging test has been made by TBA experiments, examining the effect of localization and explaining the results in terms of the length scale of molecule. ${ }^{4}$ The result obtained in this study suggests that physical aging at different temperatures involves different scales of relaxation. Although this is not a direct conclusion of the DSC measurement because it does not probe any length scales but enthalpy difference, this is based on the assumption that dimension of chain segment for relaxation depends on potential energy barrier. As observed in Figure 8, aging effect

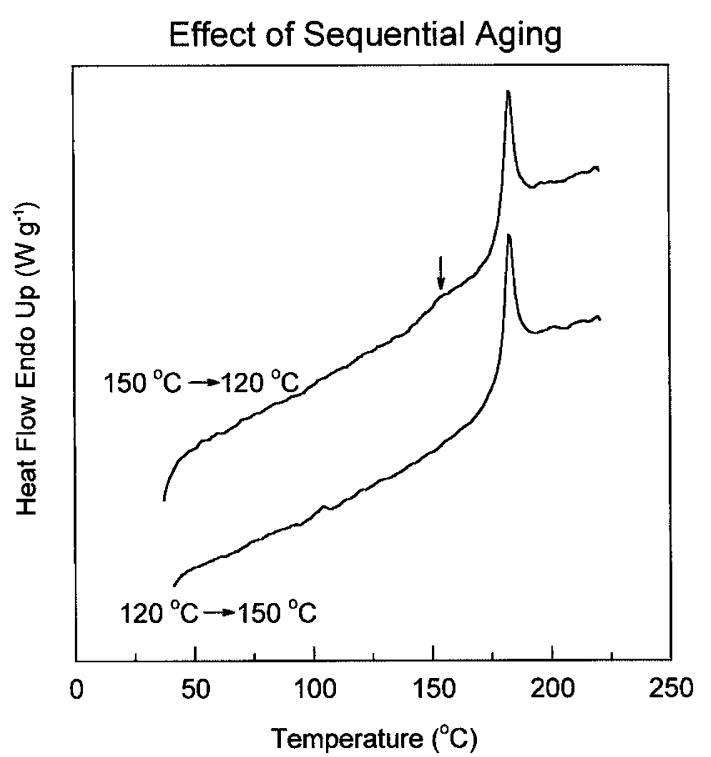

Figure 8. Sequential aging at two sub- $T_{\mathrm{g}}$ aging temperatures.

at a higher temperature $\left(T_{\mathrm{a} 2}\right)$ was not affected by subsequent aging at a lower temperature $\left(T_{\mathrm{a} 1}\right)$ which may only involve relaxation of smaller scale chain segments. On the other hand, the aging effect at $T_{\mathrm{a} 1}$ was erased when the temperature was raised to $T_{\mathrm{a} 2}$. This may involve the relaxation of longer chain segments that include those of smaller scale upon subsequent aging at the higher temperature.

When a specimen is isothermally aged at a temperature, it is concluded that the following behavior takes place depending on heating temperatures. The aging effect below $T_{\mathrm{g}}$ can be completely removed by heating above $T_{\mathrm{g}}$. During heating between $T_{\mathrm{g}}$ and $T_{\mathrm{a}}$, aging and de-aging compete each other, leading to partial erasure of the aging effect. Upon heating below $T_{\mathrm{a}}$, further aging progresses.

\section{CONCLUSION}

Since the erasure of the physical aging effect below the glass transition temperature is of importance practically as well as theoretically, one of the common techniques in studying physical aging, DSC, was applied to investigate the erasure behavior. Relaxation enthalpy peak after the isothermal aging at different aging temperatures appeared in the form of a small (at lower $T_{\mathrm{a}}$ ) or sharp (at higher $T_{\mathrm{a}}$ ) peak depending on aging temperature on DSC thermogram. Enthalpy relaxation obtained from area difference of DSC curves for aged and de-aged specimen was used as a parameter of erasure and found to be affected by erasure temperature and time during heating above $T_{\mathrm{a}}$ but below $T_{\mathrm{g}}$. At the erasure temperature close to $T_{\mathrm{g}}$, the relaxation peak area decreased suddenly with aging time, indicating fast era- 
sure of the aging effect. But, at longer period of erasure time, slight increase of enthalpy relaxation was observed, meaning that further aging occurs. However, at the erasure temperature near $T_{\mathrm{a}}$, the aging effect was removed slightly or added to the aging effect during erasing. Therefore, this experiment shows that erasure of isothermal physical aging effect does take place but partially in a competitive manner.

Acknowledgment. This paper is supported by a 2001 Research Fund from Kumoh National Institute of Technology.

\section{REFERENCES}

1. E. S. W. Kong, Abv. Polym. Sci., 80, 125 (1986).

2. R. A. Venditti and J. K. Gillham, J. Appl. Polym. Sci, 45, 501
(1992).

3. K. P. Pang and J. K. Gillham, J. Appl. Polym. Sci., 38, 2115 (1989).

4. G. Wisanrakkit and J. K. Gillham, J. Appl. Polym. Sci., 42, 2465 (1991).

5. R. A. Venditti and J. K. Gillham, J. Appl. Polym. Sci., 45, 1501 (1992).

6. J. K. Lee and J. K. Gillham, J. Appl. Polym. Sci., 81, 396 (2001).

7. E. Muzeau, G. Vigier, R. Vassoille, and J. Perez, Polymer, 36, 611 (1995).

8. E. Muzeau, J. Y. Cavaille, R. Vassoille, J. Perez, and G. P. Johari, Macromolecules, 25, 5108 (1992).

9. J. M. Hutchinson, D. McCarthy, S. Montserrat, and P. Cortes, J. Polym. Sci., Part B: Polym. Phys., 34, 229 (1996).

10. S. Montserrat, P. Cortes, Y. Calventus, and J. M. Hutchinson, J. Therm. Anal., 49, 79 (1997).

11. W. D. Cook, M. Mehrabi, and G. H. Edward, Polymer, 40, 1209 (1999) 